\title{
MARCOS REGULATÓRIOS PARA O ENFRENTAMENTO DA COVID-19: A EXPERIÊNCIA DE SOBRAL-CEARÁ
}

REGULATORY FRAMEWORKS FOR COPING WITH COVID-19: THE EXPERIENCE OF SOBRAL-CEARÁ

NORMATIVOS PARA ENFRENTAR LA COVID-19: LA EXPERIENCIA DE SOBRAL-CEARÁ

\author{
Viviane de Morais Cavalcante ${ }^{1}$ \\ David Gabriel Ferreira Duarte 2 \\ Ismael de Vasconcelos Ferreira ${ }^{3}$ \\ Rodrigo Mesquita Araújo ${ }^{4}$ \\ Marcos Aguiar Ribeiro ${ }^{5}$ \\ José Clauber Matos Brayner 6
}

\begin{abstract}
Palabras clave: Legislación; Infección por coronavirus; Pandemia; Ley de salud.

Submetido: $30 / 11 / 20$

Aprovado: 29/12/20

\section{RESUMO}

A pandemia provocada pelo novo coronavírus impôs aos entes federativos, no ano de 2020, uma série de demandas e medidas voltadas a evitar não apenas a transmissão da Covid-19, mas principalmente o colapso do sistema de saúde. Este artigo sistematiza, por meio de estudo exploratório do tipo documental, o arcabouço jurídico acionado pelo Município de Sobral para dar segurança jurídica às medidas adotadas no curso da pandemia. o Município, localizado na zona norte do estado do Ceará, regulamentou para além da decretação dos Estados de Emergência e de Calamidade, medidas que visavam à redução do impacto no orçamento, passando pela regulação do funcionamento da máquina pública, combate às fake news, medidas assistenciais, intervenção na propriedade privada, isolamento social e processo de reabertura, o que só foi possivel com o julgado pelo Supremo Tribunal Federal da Ação Direta de Inconstitucionalidade de $n .^{0}$ 6.341, que reconheceu a competência concorrente da União, Estados e Municípios para normatizar as ações necessárias ao combate à pandemia, dada a disputa de poder entre as esferas administrativas. Os marcos normativos implementados colaboraram para a segurança jurídica, bem como adequada vigilância e assistência à saúde da população.
\end{abstract}

Autor(a) para Correspondência: José Clauber Matos Brayner Rua Pereira de Miranda, n. 1087 ap. 304 Papicu Fortaleza - CE CEP: 60.175-045 Email:clauberbrayner@hotmail.com

\footnotetext{
1. Advogada. Especialista em Administração Judiciária pela Faculdade Ateneu. Coordenadora Jurídica da Secretaria da Saúde de Sobral. E-mail: vivianedemc@hotmail.com. Orcid: https://orcid.org/0000-0002-7716-7920. 2. Advogado. Especialista em Direito e Processos Constitucionais pela Universidade de Fortaleza (UNIFOR) e em Direito Eleitoral pela Pontifícia Universidade Católica de Minas Gerais (PUC). Chefe de Gabinete da Prefeitura Municipal de Sobral. E-mail: davidgfduarte@gmail.com. Orcid: https://orcid.org/0000-0001-7354-1420.

3. Graduado em Teologia com Doutorado em Ciência da Religião pela Universidade Federal de Juiz de Fora (UFJF). Coordenador Administrativo-Financeiro da Secretaria da Saúde de Sobral(2018-2020).E-mail: ismaelferreira@ sobral.ce.gov.br. Orcid: https://orcid.org/0000-0002-3958-9946.

4. Graduado em Direito pela Universidade de Fortaleza (UNIFOR). Procurador Geral do Município de Sobral. E-mail: raraujo.adv@gmail.com.0rcid: https://orcid.org/0000-0001-7142-6795.

5. Enfermeiro. Mestre em Saúde da Família (UFC). Doutorando em Enfermagem (UNIFESP). Coordenador de Vigilância do Sistema de Saúde e Interventor do Hospital Doutor Estevam da Secretária da Saúde de Sobral. E-mail: marcosribeiro@sobral.ce.gov.br.0rcid: https://orcid.org/0000-0001-7299-8007.

6.Advogado. Mestre em Saúde da Família (UFC). Especialista em Direito Empresarial (UECE). Gerente de Editais e Projetos da Secretaria Municipal da Saúde de Sobral (2017-2020). Docente dos Cursos de Direito e Administração da Faculdade Luciano Feijão. E-mail: clauberbrayner@hotmail.com. Orcid: https://orcid.org/0000-0001-7810-9856.
} 


\section{ABSTRACT}

In the year 2020, the pandemics caused by the new coronavirus imposed a series of demands and actions on federal organizations, aimed at preventing not only the transmission of Covid-19, but mainly the collapse of the health system. By means of a documentary type exploratory study, this article systematizes the legal framework triggered by the city of Sobral to grant legal certainty to the actions adopted in the current pandemic. The municipality, located in the northern region of the state of Ceara, has regulated, in addition to the enactment of the States of Emergency and Calamity, actions aimed to reduce the impact on the budget, including the regulation of how the public machine must operate, actions to fight fake news, assistance measures, intervention in private property, social isolation, and a reopening process; which were only possible as deemed by the Federal Court of Justice regarding the Direct Action of Unconstitutionality No. 6341, which recognized the competing competence of the Union, States, and Municipalities to standardize the actions necessary to combat the pandemics, given the power struggle between the administrative spheres. The regulatory framework that was implemented collaborated to ensure legal security and proper surveillance and health care for the population.

\section{RESUMEN}

La pandemia provocada por el nuevo coronavirus impuso, en el año 2020, a las entidades federativas una serie de demandas y medidas encaminadas a prevenir no solo la transmisión de la Covid-19, sino principalmente el colapso del sistema de salud. Este artículo sistematiza, mediante un estudio documental exploratorio, el marco legal impulsado por el municipio de Sobral para dar seguridad jurídica a las medidas adoptadas en el transcurso de la pandemia. El municipio, ubicado en la zona norte del estado de Ceará, ha reglamentado, además del decreto de los Estados de Emergencia y Desastre, medidas que tenían como objetivo reducir el impacto en el presupuesto, incluida la regulación del funcionamiento de la maquinaria pública, combatir fake news, medidas asistenciales, intervención en la propiedad privada, aislamiento social y proceso de reapertura, que solo fue posible con lo juzgado por la Corte Suprema Federal de Acción Directa de Inconstitucionalidad $n .^{\circ}$ 6341, que reconoció la competencia competitiva de la Unión, Estados y Municipios para estandarizar las acciones necesarias para combatir la pandemia, dada la pugna de poder entre las esferas administrativas. Los marcos legales implementados colaboraron para la seguridad jurídica y adecuada vigilancia y atención de la salud de la población.

\section{INTRODUÇÃO}

A crise mundial iniciada no ano de 2020, causada pelo novo coronavírus, pôs em xeque não apenas o sistema sanitário, mas também o jurídico, tendo em vista que a excepcionalidade da situação pandêmica não estava contemplada no ordenamento pátrio.

A Declaração da Emergência em Saúde Pública de Importância Nacional (ESPIN) em decorrência da Infecção Humana pelo Sars-CoV-2 (Severe Acute Respiratory Syndrome Coronavirus 2), tratada pela Portaria n. ${ }^{\circ} 188$, de 03 de fevereiro de 2020, deu início a uma série de atos normativos buscando regulamentar o combate ao que viria ser reconhecido como pandemia pela Organização Mundial da Saúde (OMS), posto que em decorrência do princípio da indisponibilidade do interesse público, a administração pública somente pode atuar quando houver lei que autorize ou determine a sua atuação, e nos limites estipulados por essa $l e i^{1,2}$.

A Constituição Federal ${ }^{3}$, ao mesmo tempo em que reconhece a saúde como direito de todos, confere ao Estado a responsabilidade de organizar um conjunto de ações e serviços públicos de saúde capazes de reduzir os riscos de doenças e de outros agravos à saúde, bem como de garantir à população o acesso universal e igualitário às ações e serviços para a promoção, proteção e recuperação da saúde 4 .

As políticas públicas de governo adotadas pela Administração Federal levaram a uma disputa envolvendo a União, Estados e Municípios, acerca da melhor forma de combater a Covid-19. 0 embate entre os entes Federativos quanto à competência para legislar sobre o assunto culminou com a Ação Direta de Inconstitucionalidade $(A D I)^{5}$ 6.341, na qual o Plenário do Supremo Tribunal Federal (STF) confirmou, por unanimidade, o entendimento de que as medidas adotadas pelo Governo Federal, na Medida Provisória (MP) 926/20206, para 0 enfrentamento do novo coronavírus, não afastavam a competência concorrente nem a tomada de providências normativas e administrativas pelos 
Estados, pelo Distrito Federal e pelos Municípios; com isso, tornou-se possivel que as 27 unidades da Federação e os 5.570 Municípios passassem também a regular a melhor forma de enfrentar a pandemia, de acordo com a sua situação, o que não poderia ser diferente em um Estado Federativo de extensão continental.

Nesse contexto, com a confirmação do primeiro caso de contaminação pelo novo coronavírus no Município de Sobral, medidas sanitárias e gerenciais foram instituídas, apoiadas na necessidade de cuidar da saúde da população, identificando de forma precoce os casos de Covid-19 e, assim, podendo iniciar o tratamento e acompanhamento com profissionais de saúde, bem como realizar o monitoramento dos contatos de indivíduos infectados, com o propósito de quebrar a cadeia de transmissão do vírus por meio do isolamento social, que foi aplicado a partir de normas instituídas pelo Governo do Estado do Ceará, adaptando algumas situações para a realidade da nossa região, sendo que soluções pragmáticas foram implementadas com base no direito, com o único fim de proteger a população.

0 presente artigo tem por objetivo compilar de forma sistemática as principais normas jurídicas que regulamentaram o processo de combate à pandemia no Município de Sobral na busca de conferir segurança jurídica às medidas adotadas, no curso da pandemia, pelo Município.

\section{METODOLOGIA}

0 presente artigo se trata de um estudo exploratório de base documental relativo ao período de março a novembro de 2020, em que foi analisada a situação vivenciada em Sobral, Município situado na Zona Norte do estado do Ceará, a cerca de 230 km de Fortaleza, capital do Estado, possuindo uma população estimada em 210.711 habitantes, sendo o quinto Município mais povoado do Ceará, com densidade demográfica de $88,67 \mathrm{hab} . / \mathrm{km}^{2}$, e sede da macrorregião de saúde, que engloba 55 municípios. A pesquisa foi realizada no Diário Oficial do Município, utilizando como critério de inclusão as normas que tratassem direta ou indiretamente do combate à pandemia, desde que não tratassem do mesmo assunto, as quais foram divididas em oito grupos: Estado de Emergência e Estado de Calamidade; regulação do funcionamento da máquina pública; combate às fake news; medidas assistenciais; intervenção na propriedade privada; isolamento social; impacto no

\section{“Até o dia 25 de outubro de 2020 contabilizávamos 12.515 casos positivos de Covid-19"}

orçamento e processo de reabertura, levando-se em consideração a finalidade de cada norma.

Com base na Resolução 510/20167 do Conselho Nacional de Saúde (CNS), o presente estudo seguiu todos os princípios éticos necessários às pesquisas em Ciências Humanas e Sociais, estando dispensado do registro e avaliação pelo sistema do Comitê de Ética em Pesquisa da Comissão Nacional de Ética em Pesquisa (CEP/CONEP), por utilizar informações de domínio e de acesso público.

\section{RESULTADOS E DISCUSSÃO}

\section{Do Estado de Emergência, de Calamidade e o funcionamento da máquina pública municipal}

A declaração de pandemia feita pela OMS, em 11 de março de 2020, em razão da proliferação do novo coronavírus, levou os Governos dos Estados e Municípios do país a buscarem medidas normativas que permitissem enfrentar com agilidade e dentro da legalidade o inimigo que se alastrava pelo mundo ${ }^{8}$.

Em Sobral, a publicação dos Decretos n. ${ }^{\circ} 2.370^{\circ}$, de 13 de março de 2020, que instituiu o Plano Municipal de Contingência para o coronavírus; $n .^{\circ}$ $2.371^{10}$, de 16 de março de 2020, que estabeleceu o Estado de Emergência no âmbito do Município, e n. ${ }^{\circ}$ $2.409^{11}$, de 21 de abril do mesmo ano, que declarou o Estado de Calamidade, deram início à maior batalha que já enfrentamos, tendo em vista que até o dia 25 de outubro de 2020 contabilizávamos 12.515 casos $^{12}$ positivos de Covid-19.

Com essas decisões, foi autorizada a realização de dispensa de licitação para a aquisição de bens, serviços e insumos de saúde destinados ao enfrentamento da Emergência de Saúde Pública de Importância Internacional (ESPII) decorrente do novo coronavírus, bem como foi autorizada a contratação direta de profissionais de saúde - especialmente os diretamente relacionados à assistência à saúde, observando-se a Medida Provisória n. ${ }^{0}$ 922, de 28 
de fevereiro de 2020, que altera a Lei Federal $n .^{\circ}$ 8.745, de 9 de dezembro de 1993, que dispõe sobre a contratação por tempo determinado para atender à necessidade temporária de excepcional interesse público $0^{13}$.

Regras foram instituídas em relação aos processos administrativos, ante à necessidade de garantir o amplo acesso às informações, possibilitando assim o exercício do contraditório e ampla defesa, como a suspensão dos prazos administrativos junto aos órgãos da administração pública direta e indireta do Município de Sobral, por meio do Decreto n. ${ }^{\circ} 2.381$, de 24 de março de 2020 e Decreto n. ${ }^{\circ} 2.389$, de 30 de março de 2020, bem como foi regulamentada a realização de atos processuais por videoconferência, no âmbito dos processos disciplinares da Prefeitura de Sobral, por intermédio do Decreto n. ${ }^{\circ} 2.487$, de 18 de agosto de 2020 , tendo em vista as restrições para a realização de audiências presenciais em virtude da observância do isolamento social e a necessidade de regulamentar os atos processuais, no âmbito dos procedimentos disciplinares, de maneira remota. Em 05 de julho de 2020, através do Decreto n. ${ }^{0} 2.460$, de 24 de março de 2020, houve a prorrogação da suspensão dos prazos administrativos junto aos órgãos da administração pública direta e indireta do Município de Sobral, bem como a prorrogação de vencimentos de taxas ${ }^{14-16}$.

As sessões de julgamento do Contencioso Administrativo Tributário do Município de Sobral (CONTRIM) puderam ser realizadas de forma não presencial por meio de videoconferência ou tecnologia similar, na forma estabelecida pelo Presidente do Órgão, no período de vigência do Estado de Emergência, conforme disposto no Decreto n. ${ }^{0} 2.451^{17}$, de 19 de junho de 2020.

Para que os funcionários públicos municipais pudessem permanecer em suas residências, promovendo assim o isolamento social, foi decretado ponto facultativo para o expediente dos dias 19 e 20 de março de 2020 em todos os órgãos e entidades da administração pública municipal de Sobral, conforme Decreto n. ${ }^{0} 2.373^{18}$, de 17 de março de 2020.

\section{Do Combate às Fake News}

0 cenário da pandemia foi propício para a propagação de falsas notícias (fake news) por meio das mídias sociais. De modo que, durante a pandemia, a disseminação de notícias falsas contribui para 0 descrédito da ciência e das instituições globais de

\section{"Durante a pandemia, a disseminação de notícias falsas contribui para o descrédito da ciência e das instituições globais de saúde pública"}

saúde pública, bem como enfraqueceu a adesão da população aos cuidados necessários de prevenção, ao lidar com a pandemia ${ }^{19}$.

A facilidade e velocidade da propagação de inverdades e o impacto que estas podem gerar foram os motivos que impulsionaram a edição da Lei Municipal n. ${ }^{0} 1.994^{20}$, de 08 de abril de 2020, que estabelece penalidades administrativas a quem divulgar informação falsa, cujo descumprimento poderá gerar multa, podendo dobrar o valor aplicado caso o conteúdo da infração esteja relacionado à Covid-19 e cometida durante período de Emergência ou Calamidade Pública no Município.

Visando à regulação da lei supramencionada, o Decreto $n .^{0} 2.433^{20}$, de 21 de maio de 2020, estabelece o rito do procedimento administrativo que, comprovando-se a notícia falsa, além da aplicação de multa, culminará no encaminhamento do procedimento às autoridades competentes para a apuração da conduta sob a ótica penal e civil.

\section{Das medidas Assistenciais}

As orientações dos órgãos sanitários em relação aos cuidados para evitar o contágio da Covid-19 foram amplamente divulgadas à população, tais como evitar aglomerações, optar por permanecer em suas residências, higienizar constantemente as mãos com água e sabão, cuidar da limpeza de seus objetos e dos ambientes em que estão expostos. Previu-se que o consumo de água aumentaria substancialmente nas residências, o que levou à edição do Decreto $n .^{\circ}$ $2.375^{21}$, de 18 de março de 2020, que dispõe sobre readequação dos valores concernentes às tarifas de água e esgoto no âmbito do serviço autônomo de água e esgoto de Sobral, ficando concedido o desconto de $10 \%$ nas faturas das unidades consumidoras enquadradas na Categoria Residencial e que tiverem um consumo de até $20 \mathrm{~m}^{3}$; além disso, foi garantida a isenção da cobrança de tarifa de água e esgoto às unidades consumidoras enquadradas na Categoria 
Residencial, em que consumo mensal de água fosse menor ou igual a $20 \mathrm{~m}^{3}$, cujas famílias estivessem regularmente cadastradas nos Programas Sociais do Governo e possuíssem Número de Identificação Social (NIS), até cessarem os efeitos do Decreto Municipal de Emergência n. ${ }^{0} 2.371^{10}$. Também ficaram suspensos os serviços de corte de fornecimento de água das unidades consumidoras enquadradas na Categoria Residencial, cujo consumo mensal de água fosse menor ou igual a $10 \mathrm{~m}^{3}$.

Entendendo que o isolamento social é medida eficaz para evitar a proliferação do novo coronavírus, mas ciente do impacto econômico, em especial à população mais carente, assim como às pessoas jurídicas de direito privado, o poder público expediu o Decreto n. ${ }^{0} 2.394^{22}$, de 03 de abril de 2020, que suspendeu por 90 dias os atos de inscrição de débitos em dívida ativa, salvo para evitar a prescrição, o encaminhamento para protesto de certidões de dívida ativa e o ajuizamento de execuções fiscais à exceção da necessidade de se evitar a prescrição da pretensão Fazendária.

Ainda em relação ao impacto econômico causado pelas ações essenciais de enfrentamento à pandemia causada pelo novo coronavírus, o Poder Público Municipal preocupou-se com os profissionais que de alguma forma tiveram suas rotinas de trabalho alteradas. Em Sobral, a partir da edição da Lei Municipal n. ${ }^{0}$ 1.995, de 08 de abril de 2020, que autoriza, temporariamente, o Poder Público a adotar medidas assistenciais excepcionais em favor da categoria de mototaxistas e taxistas cadastrados pela Secretaria Municipal de Serviços Públicos (Sesep), foram disponibilizados a esses profissionais uma cesta básica e o auxílio financeiro no valor de $\mathrm{R} \$$ 50,00 , em razão da interrupção de suas atividades, conforme o Decreto n. ${ }^{0}$ 2.402, de 08 de abril de $2020^{23}$.

Outras famílias socialmente vulneráveis também receberam amparo do Poder Público. Com isso, por meio do Decreto n. ${ }^{\circ} 2.380$, de 23 de março de 2020,

\section{“0 poder público} municipal preocupou-se com os profissionais que de alguma forma tiveram suas rotinas de trabalho alteradas" o auxílio financeiro do Programa Crescer Bem em Sobral, instituído pela Lei $n .^{0} 1.780$, de 12 de julho de 2018, com valor e critérios estipulados no seu art. $2^{\circ}$ e regulamentado por meio do Decreto $n .^{\circ}$ 2.283, de 22 de outubro de 2019, ficou acrescido de $\mathrm{R} \$ 50,00$ em cada uma de suas faixas, ao longo da duração do Estado de Emergência estabelecido pelo Decreto n. ${ }^{0} 2.371$, de 16 de março de $2020^{24}$.

0 s servidores públicos efetivos, comissionados e temporários da área da saúde receberam Gratificação por Trabalho Técnico Relevante (GTTR), instituída na Lei n. ${ }^{0}$ 1.607, de 02 de fevereiro de 2017, e regulamentada pelo Decreto $n .^{0} 1.823^{25}$, de 16 de fevereiro de 2017, considerando o efetivo desempenho das atividades relacionadas ao enfrentamento do novo coronavírus, com fundamento na Lei $n .^{\circ}$ $2.003^{26}$, de 26 de maio de 2020, o que se configura como reconhecimento importante ao trabalho, compromisso e dedicação desses profissionais durante a pandemia.

Com a orientação do Governo do Estado do Ceará de prorrogar a política de isolamento social rígido no Município de Sobral, instituída por intermédio do Decreto Estadual n. ${ }^{0} 33.608^{27}$, de 30 de maio de 2020, e entendendo as consequências dessa restrição de mobilidade, o Poder Público Municipal prorrogou para o dia 20 de agosto de 2020 o vencimento da cota única do Imposto Sobre a Propriedade Predial e Territorial Urbana (IPTU) do corrente ano, com o desconto de $10 \%$, através da publicação do Decreto n. ${ }^{\circ} 2450^{28}$, de 19 de junho de 2020.

Também foi prorrogado até o dia 31 de maio de 2020 o prazo para recolhimento/pagamento dos tributos municipais - Taxa de Licença para Funcionamento de Estabelecimento de Produção, Comércio, Indústria, Prestação de Serviços e Similares e Taxa de Registro e Inspeção Sanitária - com vencimentos entre os dias 23 de março a 30 de maio de 2020, bem como o prazo para o vencimento de todos os Alvarás de Funcionamento com validade entre os dias $23 \mathrm{de}$ março a 30 de maio de 2020 e o vencimento de todos os Alvarás Sanitários com validade entre os dias 23 de março a 30 de maio de 2020, conforme disposto no Decreto $n .{ }^{0} 2.419^{29}$, de 07 de maio de 2020.

\section{Da intervenção na proprietade privada}

Para a abertura do hospital de campanha e ocupação de hospital privado para suporte no recebimento de casos suspeitos e confirmados de Covid-19, o Município fez requisição administrativa 
de equipamentos privados. Os Decretos n. ${ }^{\circ} 2.369$, de 13 de março de 2020 e n. ${ }^{\circ} 2.377$, de 20 de março de 2020, cuidaram de regulamentar a intervenção no Hospital Doutor Estevam Ponte e Clínica Doutor Francisco Alves, respectivamente, sendo que, neste último prédio, foi instalado o Hospital de Campanha Covid-19 Doutor Francisco Alves, que já teve a intervenção prorrogada por força do Decreto n. ${ }^{0} 2.508$, de 29 de setembro de 2020. Essas ações tiveram impacto na ampliação da rede de atenção à saúde, sobretudo em relação ao aumento de leitos para pacientes suspeitos e confirmado de Covid-19, tendo em vista que Sobral é sede da Macrorregião Norte de Saúde, que atende cerca de 1.669 .655 habitantes. Ao todo, foram criados 84 leitos clínicos e dez leitos de Unidade de Terapia Intensiva(UTI) ${ }^{30-33}$.

Para o regular funcionamento desses hospitais, foi necessário providenciar a criação de 483 cargos públicos, por meio dos Decretos n. ${ }^{\circ} 2.387$, de 29 de março de 2020, e n. ${ }^{\circ} 2.426$, de 09 de maio de 2020, autorizando a Secretaria Municipal da Saúde (SMS) a realizar a contratação de profissionais por tempo determinado para atender à necessidade temporária de excepcional interesse público, considerando o Estado de Emergência decretado ${ }^{34}$. A contratação temporária desses profissionais foi efetivada através da realização de três seleções públicas simplificadas voltadas à contratação de profissionais para 0 enfrentamento da pandemia.

Outra intervenção municipal por modalidade de requisição administrativa foi realizada para viabilizar a recomendação da Organização Mundial de Saúde quanto ao uso de máscaras, de forma a evitar o contágio da Covid-19, bem como em razão da imprescindível utilização de máscaras pelos profissionais da área de saúde e por toda a população sobralense, as quais se apresentavam escassas no mercado brasileiro. Com a publicação do Decreto n. ${ }^{\circ} 2.396$, de 04 de abril de 2020, alterado pelo Decreto n. $2.412^{35}$, de 24 de abril de 2020, foram requisitadas para a utilização na fabricação de máscaras de uso pessoal da população todas as instalações físicas da empresa Diamantes Lingerie, localizada no Distrito Industrial de Sobral, Ceará, englobando tudo o que era necessário para o seu regular e efetivo funcionamento.

\section{Do isolamento social}

Como única forma de conter a disseminação do vírus, o Decreto n..$^{2} 2.437^{36}$, de 31 de maio de
2020, instituiu no Município de Sobral a política do isolamento social rígido como medida de enfrentamento da Covid-19, em observância ao Decreto Estadual n. ${ }^{0} 33.608^{27}$, de 30 de maio de 2020, uma vez que a imprescindibilidade de medidas mais restritivas se impõe, a partir do entendimento de que a vida do cidadão é o direito fundamental de maior expressão constitucional, sendo obrigação do Poder Público, em situações excepcionais, agir com o seu legítimo poder de polícia para a proteção das garantias e direitos constitucionais, adotando as ações necessárias, por mais que, para tanto, restrições a outros direitos sejam indispensáveis.

As medidas de restrição de mobilidade e funcionamento do comércio em geral foram orientadas a partir de Decretos Municipais que, semanalmente, com base em dados epidemiológicos, foram publicados com as diretrizes sobre as limitações do funcionamento das atividades, fechamento do mercado público, bancos e lotéricas, considerando a necessidade de se estabelecer um plano de resposta efetivo para essa condição de saúde de ampla repercussão populacional, no âmbito do Brasil e do Município de Sobral. Fez-se necessário regulamentar a organização de atendimentos bancários, haja vista que esses locais constituem pontos nevrálgicos para eventual contaminação em massa pelo novo coronavírus, bem como considerando que a grande maioria das pessoas a serem atendidas nas agências bancárias e congêneres são pessoas carentes e que possuem menos condições de isolamento social; portanto, são mais suscetíveis à contaminação. Em verdade, controlar as filas e aglomerações nas agências bancárias e casas lotéricas foi um dos grandes desafios para tornar efetivo o isolamento social.

\section{Do impacto no orçamento}

Diante dessas ações mais restritivas e que 
impactaram diretamente a economia da cidade de Sobral, coube à gestão municipal também estabelecer medidas a fim de reduzir custos na administração pública municipal, na busca por evitar a demissão de trabalhadores, visto que a arrecadação municipal apresentou queda significativa, acarretando impacto imediato e significativo nas finanças do Município, decorrente da desaceleração brusca da atividade econômica provocada pela pandemia.

Para isso, a câmara municipal aprovou a Lei n. ${ }^{\circ} 1.998^{37}$, em 30 de abril de 2020, autorizando o poder executivo a estabelecer diretrizes para 0 contingenciamento de gastos de todos os órgãos do poder executivo municipal, considerando a decretação dos Estados de Emergência e de Calamidade para o enfrentamento do novo coronavírus, e dando outras providências. Com a publicação da citada Lei, editouse o Decreto $n .{ }^{0} 2.415^{38}, 30$ de abril de 2020, que estabeleceu diretrizes para o contingenciamento de gastos proposto.

Foram consideradas, nesse contingenciamento, a postergação para o ano de 2021 das promoções e progressões funcionais dos servidores públicos municipais, a vedação de nomeação de candidatos aprovados em concurso e a redução de valores de representações de cargos de provimento em comissão e gratificações financeiras (Gratificação por Trabalho Técnico Relevante - GTTR). Ressaltase que essas restrições não foram aplicadas aos profissionais relacionados aos serviços de saúde e saneamento, dada a especificidade do evento que motivou tais medidas. Isso garantiu que as contas do poder executivo não sofressem um desequilíbrio financeiro, o que tornaria mais grave a crise, podendo acarretar comprometimentos fiscais.

Outras providências para o ajuste das contas públicas também foram implementadas, as quais foram realizadas devido aos aportes e incentivos financeiros recebidos do Ministério da Saúde para as ações de enfrentamento da pandemia. Como é de praxe, o planejamento orçamentário para o ano de 2020 foi elaborado em 2019. Naquela ocasião, não se tinha nenhuma perspectiva acerca do cenário pandêmico vivenciado. Desse modo, foi necessário, nesse ano, adequar os valores orçamentários, bem como os contratos da Secretaria da Saúde, através de procedimentos administrativos e jurídicos, com a realização de remanejamentos orçamentários, solicitações de crédito suplementar ao orçamento, apostilamentos e aditivos de contratos. Com a publicação do Decreto $n .^{0} 2.420^{39}$, de 08 de maio

\section{"As restrições adotadas surtiram efeito, de modo que, com a redução da taxa de contaminação e ocupação de leitos, permitiu-se o processo de reabertura responsável das atividades"}

de 2020, foi estabelecida a abertura de um crédito adicional ao orçamento vigente.

Todos esses procedimentos foram precedidos de atos e publicações oficiais a fim de garantir o cumprimento aos princípios da administração pública, tais como a legalidade, a moralidade e a publicidade. As publicações foram realizadas em permanente contato e consenso com outras Secretarias do Município, caracterizando o emprego da solidariedade e, sobretudo, do compartilhamento da responsabilidade entre os entes públicos. Essas ações foram essenciais na alocação de mais de 50 milhões de reais recebidos pelo Fundo Municipal de Saúde e empregados nas ações e serviços de enfrentamento da Covid-19.

\section{Do processo de reabertura}

As restrições adotadas surtiram efeito, de modo que, com a redução da taxa de contaminação e ocupação de leitos, permitiu-se o processo de reabertura responsável das atividades econômicas e comportamentais, com cautela e atenção, baseando-se no entendimento dos especialistas da saúde, sem prescindir do isolamento social e de sua regionalização como políticas públicas de enfrentamento da pandemia, comprometidas, acima de tudo, com a vida do cidadão.

0s Decretos de n. ${ }^{\circ} 2.469$, de 19 de julho de 2020; n. ${ }^{\circ} 2.477$, de 02 de agosto de 2020; n. ${ }^{2} 2.482$, de 09 de agosto de 2020 e n. 2.486 , de 15 de agosto de 2020, deram início às quatro primeiras fases do processo de reabertura, mantendo, porém, o isolamento social, perdurando esta última fase até a finalização do levantamento dos dados ${ }^{40}$.

Ao se tratar da abertura de atividades econômicas e comportamentais, cuidou-se em condicionar esse processo de retomada da economia à observância, 
por parte dos setores liberados, de medidas sanitárias definidas pelas autoridades de saúde como necessárias para evitar qualquer mínimo retrocesso no trabalho desenvolvido até hoje pelo Município, no combate à Covid-19, o qual sempre se baseou na ciência e em ações responsáveis, sobretudo seguras para a vida da população.

\section{CONCLUSÃO}

Após oito meses desde o surgimento dos primeiros casos de Covid-19 no Município de Sobral, mais de 70 atos normativos foram baixados buscando regular o combate à pandemia, já que a necessidade de fundamentar as ações do Município fez com que, quase que diariamente, fosse publicado um decreto tratando do assunto.

Ao efetuar o levantamento normativo que deu base e sustentação legal às ações municipais voltadas a evitar a disseminação do vírus, foi possivel a classificação dos atos em oito grupos: Estado de Emergência e de Calamidade; regulação do funcionamento da máquina pública; combate às fake News; medidas assistenciais; intervenção na propriedade privada; isolamento social; impacto no orçamento e processo de reabertura.

0 presente estudo buscou efetuar um levantamento dos principais atos normativos que permitiram à administração pública desenvolver ações voltadas à redução dos riscos da população frente à crise sanitária que se abateu em nosso país, principalmente em decorrência das disputas políticas envolvendo as três esferas de governo.

\section{CONTRIBUIÇÃO DOS AUTORES}

Viviane de Morais Cavalcante contribuiu com redação, análise e revisão crítica do manuscrito. David Gabriel Ferreira Duarte contribuiu com redação, análise e revisão crítica do manuscrito. Ismael de Vasconcelos Ferreira contribuiu com redação, análise e revisão crítica do manuscrito. Rodrigo Mesquita Araújo contribuiu com redação, análise e revisão crítica do manuscrito. Marcos Aguiar Ribeiro contribuiu com redação, análise e revisão crítica do manuscrito. José Clauber Matos Brayner contribuiu com redação, análise e revisão crítica do manuscrito.

\section{REFERÊNCIAS}

1. Brasil. Portaria n. ${ }^{0} 188$, de 3 de fevereiro de 2020. Declara emergência em Saúde Pública em Importância Nacional (ESPIN) [document on the internet]. Diário Oficial da União, Brasília (2020 Feb 04 [cited 2020 Dec 29]); Sec 1. Available from: https://www.in.gov.br/en/web/dou/-/portaria-n188-de-3-de-fevereiro-de-2020-241408388

2. Alexandrino $M$, Paulo $V$. Direito administrativo descomplicado. 19. ed. Rio de Janeiro: Método; 2009.

3. Brasil. Constituição da República Federativa do Brasil. Brasília (DF): Senado Federal; 1988.

4. Aith F. Perspectivas do direito sanitário no Brasil: as garantias jurídicas do direito à saúde e os desafios para sua efetivação. In: Santos L, organizador. Direito da saúde no Brasil. Campinas: Saberes Editora; 2010. p. 183-238.

5. Brasil. Supremo Tribunal Federal (STF). Ação Direta de Inconstitucionalidade 6341. Brasília (DF): Senado Federal; 2020.

6. Brasil. Medida provisória n.$^{\circ} 926$, de 20 de março de 2020. Altera a lei n. ${ }^{0} 13.979$, de 6 de fevereiro de 2020 [document on the internet]. Diário Oficial da União, Brasília (2020 Mar 20 [cited 2020 Dec 28]). Available from: http://www.planalto.gov. br/ccivil 03/ato2019-2022/2020/Mpv/mpv926. htm\#: : text=MEDIDA \%20PROVIS\%C $3 \% 93$ RIA $\% 20$ $\mathrm{N} \% \mathrm{C} 2 \% \mathrm{BA} \% 20926 \% 2 \mathrm{C} \% 20 \mathrm{DE} \% 2020 \% 20 \mathrm{DE} \% 20$ MAR\%C3\%870\%20DE\%202020\&text=Altera\%20 a \% 20 Lei $\% 20$ n \% C $2 \%$ B A \% 2013.979 , import $\%$ C$3 \%$ A 2 ncia $\% 20$ internacional $\% 20$ decorrente $\% 20$ do $\% 20$ coronav $\%$ C $3 \%$ ADrus

7. Brasil. Resolução n. ${ }^{0}$ 510, de 01 de abril de 2016. Dispõe sobre as normas aplicáveis a pesquisa em ciências humanas e sociais [document on the internet]. Diário Oficial da União, Brasília (2016 Apr 01 [cited 2020 Dec 18]). Available from: http:// bvsms.saude.gov.br/bvs/saudelegis/cns/2016/ res0510 $0704 \quad 2016 . h t m$

8. Martins RU, Araújo VA, Silva RN, Tavares BLL, Barcelos LSO, Silva RA. Saúde mental dos profissionais da atenção básica em tempos de pandemia. Cad ESPCE [serial on the internet]. 2020 [cited 2020 Nov 17];14(1). Available from: https://cadernos.esp. ce.gov.br/index.php/cadernos/article/view/373/226

9. Sobral. Decreto n. ${ }^{0}$ 2.370, de 13 de março de 2020. Institui o plano municipal de contingência para o coronavírus [document on the internet]. Diário Oficial do Município, Sobral (2020 Mar 13 [cited 2020 Dec 18]); Ano IV, n. ${ }^{0} 757$. Available from: http://transparencia.sobral.ce.gov.br/arquivo/nome :352d4d59debb8f77678c8e1d3c50cac6.pdf

10. Sobral. Decreto n. ${ }^{0} 2.371$, de 16 de março de 2020 . 
Decreta estado de emergência no âmbito do Município de Sobral e estabeleceu medidas para enfrentamento do novo coronavírus (COVID-19) [document on the internet]. Diário Oficial do Município, Sobral (2020 Mar 16 [cited 2020 Dec 18]). Available from: http://www.sobral.ce.gov.br/diario/public/files/ diario/9bf7ba4ae2931bdf14b3a48b5240d141.pdf

11. Sobral. Decreto n. ${ }^{0} 2.409$, de 21 de abril de 2020 . Decreta estado de calamidade municipal [document on the internet]. Diário Oficial do Município, Sobral (2020 Apr 21 [cited 2020 Dec 18]). Available from: http:// www.sobral.ce.gov.br/diario/public/files/diario/9 5822788b5ca1d4051f94274277f483d.pdf

12. Brasil. Indicadores IntegraSUS [home-page on the internet]. Brasília (DF): Ministério da Saúde; 2020. [cited 2020 nov 29]. Available from: https:// indicadores.integrasus.saude.ce.gov.br/indicadores

13. Brasil. Medida provisória n. ${ }^{\circ}$ 922, de 28 de fevereiro de 2020 [document on the internet]. Diário Oficial da União, Brasília (2020 Feb 28 [cited 2020 Dec 18]). Available from: https://www.in.gov.br/ en/web/dou/-/medida-provisoria-n-922-de-28-defevereiro-de-2020-245480247

14. Sobral. Decreto n. ${ }^{0} 2419$, de 07 de maio de 2020. Decreta a prorrogação de prazos para pagamentos de determinadas taxas, da suspensão dos processos administrativos da administração pública direta e indireta do município de Sobral [document on the internet]. Diário Oficial do Município, Sobral (2020 May 07 [cited 2020 Dec 18]) 2020. Available from: http://transparencia.sobral. ce.gov.br/arquivo/nome:bc797a30dcc4a9eb6056bb2 egd8abf0e.pdf

15. Sobral. Decreto n. ${ }^{0} 2487$, de 18 de agosto de 2020. Regulamenta a realização de atos processuais por videoconferência no âmbito dos processos disciplinares da prefeitura de Sobral [document on the internet]. Diário Oficial do Município, Sobral (2020 Aug 18 [cited 2020 Dec 19]). Available from: http://transparencia.sobral.ce.gov.br/arquivo/ nome:925773d58388c9481615b6b745d615e3.pdf

16. Sobral. Decreto n. ${ }^{0} 2.460$, de 05 de julho de 2020. Decreta a prorrogação da suspensão dos prazos administrativos junto aos órgãos da administração pública direta e indireta do município de sobral, a prorrogação de vencimentos de taxas [document on the internet]. Diário Oficial do Município, Sobral (2020 July 05 [cited 2020 Dec 21]). Available from: http://www.sobral.ce.gov.br/diario/public/files/ diario/a3705c0ec2f48baa93ab5f84ec39892b.pdf

17. Sobral. Decreto n. ${ }^{0}$ 2.451, de 19 de junho de 2020 - autoriza a realização de sessão de julgamento não presencial, por meio de vídeo conferência ou tecnologia similar, no âmbito do contencioso administrativo tributário do município de Sobral [document on the internet]. Diário Oficial do
Município, Sobral (2020 July 19 [cited 2020 Dec 08]). Available from: http://www.sobral.ce.gov.br/ diario/public/files/diario/977af4ed34dc00d6f7b167 283e513ae2.pdf

18. Sobral. Decreto n. ${ }^{\circ} 2.373$, de 17 de março de 2020. Decreta ponto facultativo para o expediente dos dias 19 e 20 de março de 2020 em todos os órgãos e entidades da administração pública municipal de Sobral [document on the internet]. Diário Oficial do Município, Sobral (2020 Mar 17 [cited 2020 Dec 18]). Available from: http://www.sobral.ce.gov.br/diario/ public/files/diario/97d8b9ed7bfe 9ef533886cc33510 5fe3.pdf

19. Galhardi CP, Freire NP, Minayo MCS, Fagundes MCM. Fato ou fake? Uma análise da desinformação frente à pandemia da Covid-19 no Brasil. Cien Saúde Colet [serial on the internet]. 2020 [cited 2020 Dec 16];25(supl 2). Available from: https://www.scielo. $\mathrm{br} / \mathrm{pdf} / \mathrm{csc} / \mathrm{v} 25 \mathrm{~s} 2 / 1413-8123-\mathrm{csc}-25-\mathrm{s} 2-4201 . \mathrm{pdf}$

20.Sobral. Lei n. ${ }^{0} 1994$ de 08 de abril de 2020. Estabelece penalidades administrativas a quem divulgar informação falsa ("fake news"), e dá outras providências [document on the internet]. Diário Oficial do Município, Sobral (2020 Apr 08 [cited 2020 Dec 12]). Available from: http:// www.sobral.ce.gov.br/diario/public/files/diario/ f8096221bc6f791efaad0061dd53ba21.pdf

21. Sobral. Decreto n. ${ }^{0} 2.375$, de 18 de março de 2020. Dispõe sobre readequação dos valores concernentes às tarifas de água e esgoto no âmbito serviço autônomo de água e esgoto de sobral [document on the internet]. Diário Oficial do Município, Sobral (2020 Mar 18 [cited $2020 \mathrm{Dec} 18$ ]). Available from: https://taxpratico.com.br/pagina/decreto-n-2375de-18-de-marco-de-2020-sobral-ce

22. Sobral. Decreto n. ${ }^{\circ} 2.394$, de 03 de abril de 2020. Decreta a Suspensão de inscrições em dívida ativa do município, Prorroga a validade das certidões negativas do Município, e dá outras providências [document on the internet]. Diário Oficial do Município, Sobral (2020 Apr 03 [cited 2020 Dec 18]). Available from: http://transparencia.sobral.ce.gov.br/arquivo Lnome:c715439ac695b53ef0c5600012401a8d.pdf

23. Sobral. Lei 1995, de 08 de abril de 2020. Autoriza, temporariamente, 0 poder executivo a tomar medidas assistencialistas excepcionais em favor da categoria de mototaxistas e taxistas cadastrados, face ao estado de emergência decorrente do coronavírus (covid-19) [document on the internet]. Diário Oficial do Município, Sobral (2020 Apr 08 [cited 2020 Dec 18]). Available from: http:// transparencia.sobral.ce.gov.br/arquivo/nome:ed2 baec8aca9aefb41d1349466c48a13.pdf

24. Sobral. Decreto n. ${ }^{0} 2.380$, de 23 de março de 2020. Estabelece o acréscimo ao auxílio financeiro do programa crescer bem em Sobral [document on 
the internet]. Diário Oficial do Município, Sobral (2020 Mar 23 [cited 2020 Dec 18]). Available from: http://transparencia.sobral.ce.gov.br/arquivo/nome :e62b3bdd6e59af0a20f0e9efe81bdd77.pdf

25. Sobral. Decreto n. ${ }^{\circ} 1.823$, de 16 de fevereiro de 2017. Dispõe sobre a regulamentação da concessão de gratificação por tempo de trabalho relevante e a concessão de auxílio de caráter indenizatório para custear despesas alimentares e de deslocamento [document on the internet]. Diário oficial do Município, Sobral (2017 Feb 16 [cited 2020 Dec 18]). Available from: http://transparencia.sobral. ce.gov.br/arquivo/nome:8ee2928ee4a05833db28975 70219fc90.pdf

26. Sobral. Lei n. ${ }^{0} 2003$, de 26 de maio de 2020. Autoriza o poder executivo a conceder, em caráter provisório, gratificação por trabalho técnico relevante aos servidores da área da saúde, considerando o enfrentamento do novo coronavírus (covid-19) [document on the internet]. Diário Oficial do Município, Sobral (2020 May 26 [cited 2020 Dec 18]). Available from: http://transparencia.sobral. ce.gov.br/arquivo/nome:5b4365540499c3baa1b8 28577d9137b9.pdf

27. Ceará. Decreto n. ${ }^{0} 33.608$, de 30 de maio de 2020. Prorroga o isolamento social no estado do Ceará [document on the internet]. Diário Oficial do Estado, Ceará (2020 May 30 [cited 2020 Dec 18]). Available from: https://www.ceara. gov.br/wp-content/uploads/2020/05/DECRET 0-N\%C2\%BA33.608-de-30-de-maio-de-2020.pdf

28. Sobral. Decreto n. ${ }^{\circ} 2450$, de 19 de junho de 2020. Prorroga para o dia 20 de agosto de 2020 o vencimento a cota única do imposto sobre a propriedade predial e territorial urbana (IPTU) do exercício de 2020 [document on the internet]. Diário oficial do Município, Sobral (2020 June 19 [cited 2020 Dec 28]). Available from: https://taxpratico.com.br/pagina/ decreto-n-2450-de-19-de-junho-de-2020-sobral-ce

29. Sobral. Decreto n. ${ }^{0} 2.418$, de 07 de maio de 2020. Intensifica as medidas de distanciamento social em razão da pandemia do novo coronavírus (covid-19) [document on the internet]. Diário Oficial do Município, Sobral (2020 May 07 [cited 2020 Dec 18]). Available from: http://www.sobral.ce.gov.br/ diario/public/files/diario/550f6e95cf8b37171a6b40 50ef2c7438.pdf

30. Sobral. Decreto n. 2.369 de 13 de março de 2020. Declara estado perigo público iminente [document on the internet]. Diário Oficial do Município, Sobral (2020 Mar 13 [cited 2020 Dec 12]). Available from: http://www.sobral. ce.gov.br/diario/public/files/diario/00ebe 5 6060c94df734b04637524ca2eb.pdf
31. Sobral. Decreto n. ${ }^{0} 2.377$, de 20 de março de 2020. Decreta intervenção municipal por modalidade de requisição do prédio e todas as instalações físicas da clínica Doutor Francisco Alves [document on the internet]. Diário Oficial do Município, Sobral (2020 Mar 20 [cited 2020 Dec 10]). Available from: http://transparencia.sobral.ce.gov.br/contrato/ detail/numero:TF02/2020-SAUDE/orgao:07

32. Sobral. Decreto n. ${ }^{0} 2.508$, de 29 de setembro de 2020. Dispõe sobre a prorrogação do decreto $n^{\circ}$ decreto $n^{\circ} 2377$, de 20 de março de 2020 [document on the internet]. Diário Oficial do Município, Sobral (2020 Sept 29 [cited 2020 Dec 10]). Available from: http://www.sobral.ce.gov.br/diario/public/files/ diario/c7f14d3bfd59d3f2dbd5fd42346d33ff.pdf

33. Brasil. Estimativas preliminares 2000 a 2020 [document on the internet]. Brasillia (DF): Ministério da Saúde; 2020. Available from: http://tabnet. datasus.gov.br/cgi/deftohtm.exe?popsvs/cnv/ popbr.def

34. Sobral. Decreto n. ${ }^{\circ} 2.387$, de 29 de março de 2020 e n. ${ }^{0} 2.426$, de 09 de maio de 2020. Autoriza a secretaria municipal da saúde a realizar contratação de profissionais por tempo determinado para atender à necessidade temporária de excepcional interesse público [document on the internet]. Diário Oficial do Município, Sobral (2020 Mar 29 [cited 2020 Dec 09]). Available from: http://transparencia. sobral.ce.gov.br/arquivo/nome:267e4b02d d651210c27eb5d1d90769c3.pdf

35. Sobral. Decreto n. ${ }^{\circ} 2412$, de 24 de abril de 2020. Dispõe sobre a alteração do decreto n. ${ }^{\circ} 2396$, de 04 de abril de 2020, que trata da intervenção municipal por modalidade de requisição do prédio e de todas as instalações físicas da diamantes lingerie [document on the internet]. Diário Oficial do Município, Sobral (2020 Apr 24 [cited 2020 Nov 28]). Available from: http://transparencia.sobral. ce.gov.br/arquivo/nome:b2b9ccba920b4478bbbd4 421ff353c69.pdf

36. Sobral. Decreto n. ${ }^{\circ} 2437$, de 31 de maio de 2020. Institui, no município de sobral, a política de isolamento social rígido como medida de enfrentamento à covid - 19, em observância ao decreto estadual $n^{\circ} 33.608$, de 30 de maio de 2020 [document on the internet]. Diário Oficial do Município, Sobral (2020 May 31 [cited 2020 Nov 28]). Available from: http://transparencia.sobral. ce.gov.br/arquivo/nome:e3b2bafbea7aabb823e08a4 751eac1c4.pdf

37. Sobral. Lei n. 1998 de 30 de abril de 2020. autoriza o poder executivo municipal a estabelecer diretrizes para o contingenciamento de gastos de todos os órgãos do poder executivo municipal, considerando a decretação do estado de emergência e de calamidade para o enfrentamento do coronavírus (covid-19) [document on the internet]. Diário Oficial do Município, Sobral (2020 Apr 30 [cited 2020 Nov 
28]). Available from: http://transparencia.sobral. ce.gov.br/arquivo/nome:344814b28f044a1f0f808ad 01cbcafa9.pdf

38. Sobral. Prefeitura Municipal de Sobral. Decreto $n^{\circ}$ 2415, 30 de abril de 2020. Estabelece diretrizes para o contingenciamento de gastos de todos os órgãos do poder executivo municipal, considerando a decretação do estado de emergência em saúde e calamidade para o enfrentamento do coronavírus (covid-19) [document on the internet]. Diário Oficial do Município, Sobral (2020 Apr 30 [cited 2020 Nov 18]). Available from: http://transparencia.sobral. ce.gov.br/arquivo/nome:17bb8572ad4727925f16dea7 $\underline{48 c 9 e 17 d . p d f}$

39. Sobral. Decreto $n^{0} 2420$, de 08 de maio de 2020 abre um crédito adicional suplementar ao orçamento vigente [document on the internet]. Diário Oficial do Município, Sobral (2020 May 08 [cited 2020 Nov 28]). Available from: http://transparencia.sobral.ce. gov.br/arquivo/nome:f18812cd2067eabaada 4558176 cfc7ca.pdf

40. Sobral. Plano de retomada das atividades produtivas e da convivência social em Sobral e respectivas regras de flexibilização do distanciamento social em razão da pandemia - COVID-19 [document on the internet]. Sobral: Prefeitura de Sobral; 2020. Available from: http://transparencia.sobral.ce.gov. br/arquivo/nome:17bb8572ad4727925f16dea748c9e1 7d.pdf
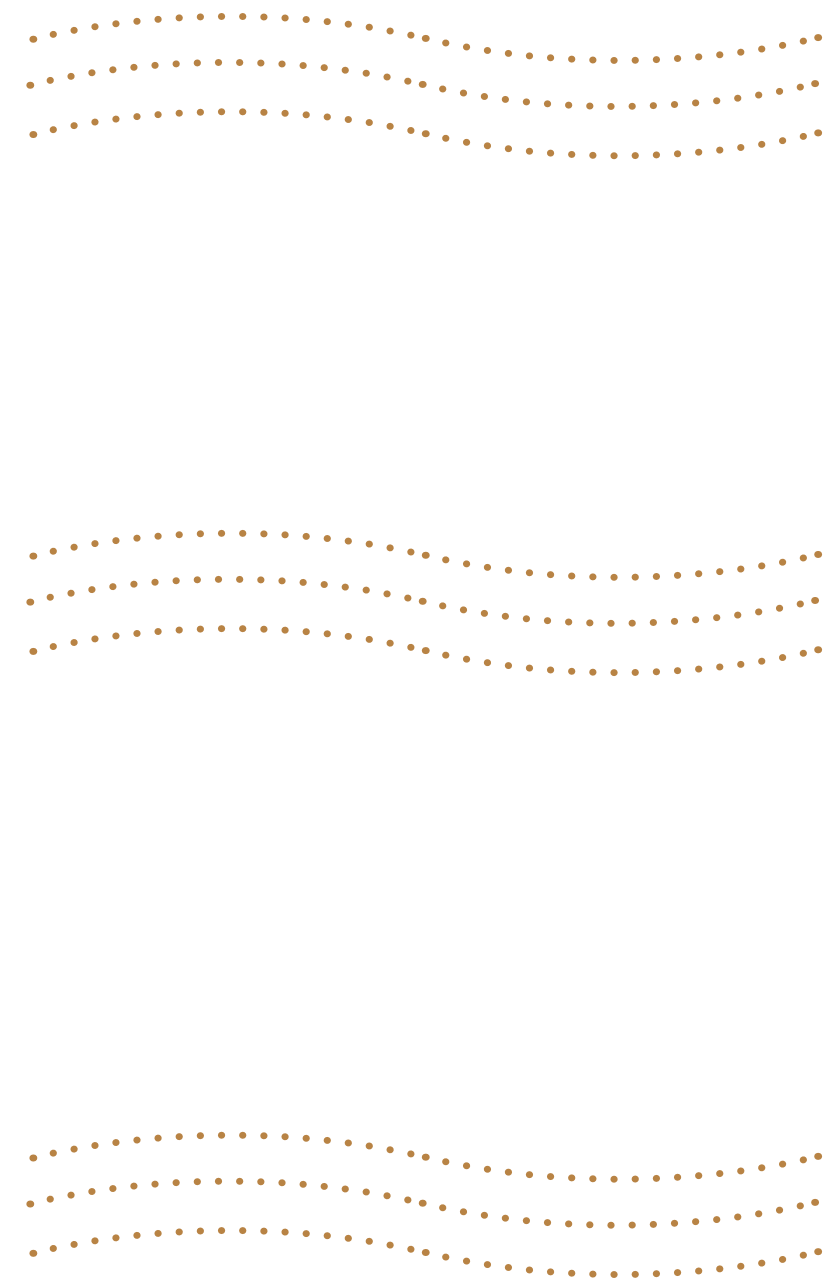
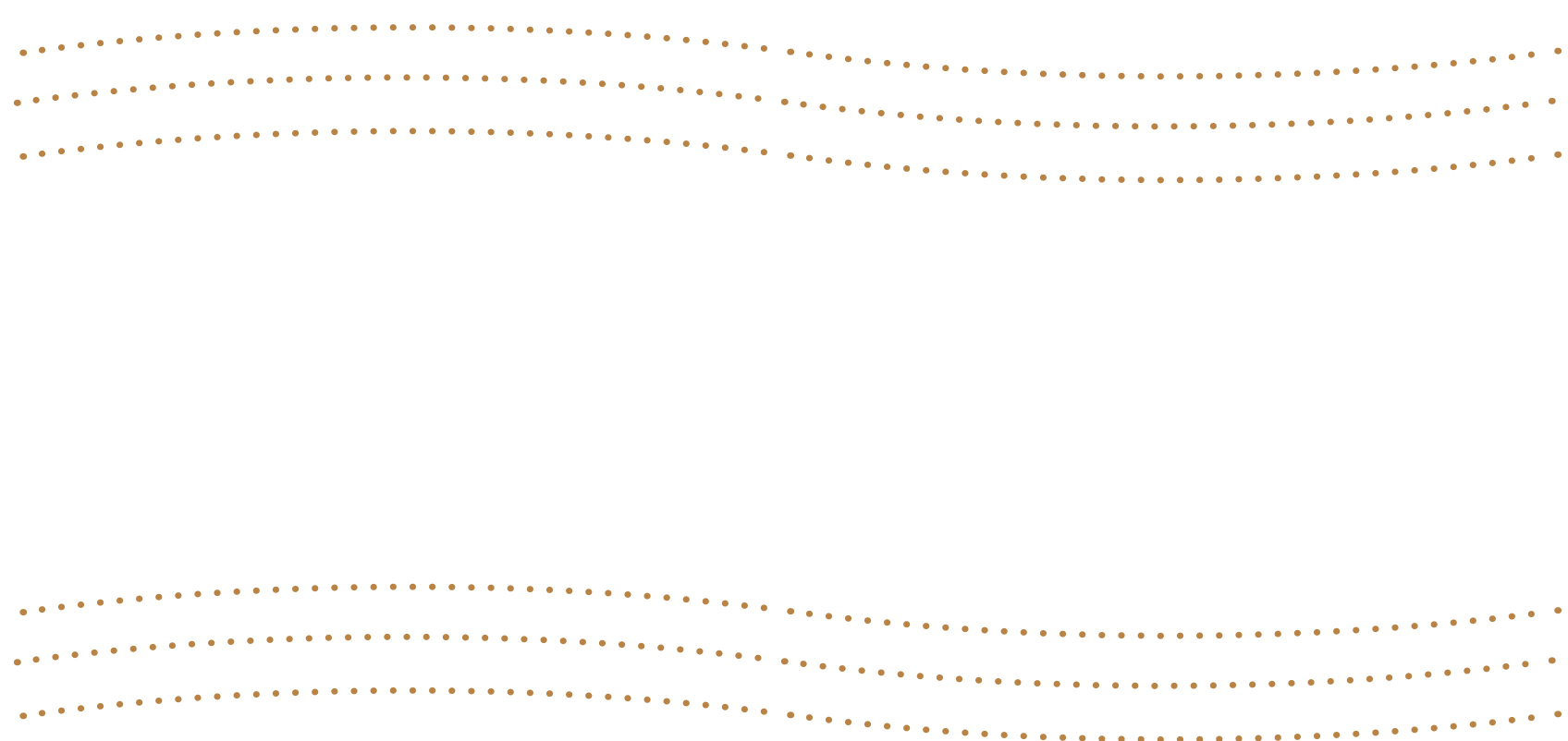